\title{
A Educação Estético-Ambiental na construção de uma cúpula geodésica: trabalho coletivo, participativo e integrador
}

\author{
Environmental Aesthetic Education in the construction of a geodesic dome: collective,
} participatory, integrative work

La Educación Estético-Ambiental en la construcción de una cúpula geodésica: trabajo colectivo, participativo e integrador

\section{Resumo}

Este artigo objetiva refletir sobre a experiência de construção de uma cúpula geodésica no âmbito da Educação Básica. Busca compreender, a partir das memórias dos participantes desse processo, os elementos vinculados aos pressupostos da Educação Estético-Ambiental que perpassaram a atividade desenvolvida. Os participantes da pesquisa foram três alunos e cinco professoras que se envolveram no processo de construção da cúpula geodésica do Instituto Federal de Ciência e Tecnologia Sul-rio-grandense - Campus Pelotas-Visconde da Graça. O corpus da pesquisa foi produzido a partir de entrevistas semiestruturadas, diário de campo e fotografias e analisado por meio da Análise Textual Discursiva, proposta por Moraes e Galiazzi. Os resultados sinalizam que o processo de construção de uma cúpula geodésica é uma potente estratégia pedagógica e metodológica para o desenvolvimento da EEA, ao engendrar o diálogo, a participação, a colaboração e a partilha. A reflexão crítica, o desenvolvimento da sensibilidade e o contato com o ambiente natural mostraram-se constantes nas várias etapas do processo, ampliando as possibilidades de uma formação integral.

Palavras-chave: Cúpula geodésica; Educação estético-ambiental; Educação básica.

\begin{abstract}
This paper aims at reflecting on the experience of constructing a geodesic dome in Elementary Education - based on participants' memories - to understand elements related to principles of Environmental-Aesthetic Education (EAE) involved in the activity under development. Participants were three students and five teachers who took part in the construction process of the geodesic dome at the Instituto Federal de Ciência e Tecnologia Sul-rio-grandense Campus Pelotas - Visconde da Graça, located in Pelotas, RS, Brazil. The corpus comprised data collected in semistructured interviews, field diaries and photographs, which were submitted to Textual Discourse Analysis, proposed by Moraes and Galiazzi. Results show that the construction process of a geodesic dome is a powerful pedagogical and methodological strategy to develop EAE, since it triggers dialogue, participation, collaboration and sharing. Critical reflection, sensitivity development and contact with the natural environment were found in all steps of the process and broadened possibilities of integral education.
\end{abstract}

Keywords: Geodesic dome; Aesthetic-environmental education; Elementary education.

\section{Resumen}

Este artículo tiene como objetivo reflexionar sobre la experiencia de construir una cúpula geodésica en el ámbito de la Educación Básica. Busca comprender, a partir de las memorias de los participantes de este proceso, los elementos vinculados a los supuestos de la Educación Estético-Ambiental (EEA) que permearon la actividad desarrollada. Los participantes de la investigación fueron tres alumnos y cinco profesoras que participaron en el proceso de construcción de la cúpula geodésica del Instituto Federal de Ciencia y Tecnología Sul-Rio-Grandense, Campus Pelotas - Visconde da Graça. El corpus de investigación se produjo a partir de entrevistas semiestructuradas, diarios de campo y fotografías, y se analizó a través del Análisis Textual Discursivo, propuesto por Moraes y Galiazzi. Los resultados muestran que el proceso de construcción de una cúpula geodésica es una poderosa estrategia pedagógica y metodológica para el desarrollo de la EEA al generar diálogo, participación, colaboración e intercambio. La reflexión 
crítica, el desarrollo de la sensibilidad y el contacto con el ambiente natural resultaron ser constantes en distintas etapas del proceso, ampliando las posibilidades de una formación integral.

Palabras clave: Cúpula geodésica; Educación estético-ambiental; Educación básica.

\section{Introdução}

Um dos desafios da sociedade contemporânea, no âmbito do ensino formal, é a sugestão de propostas pedagógicas inovadoras, cujas metodologias promovam a formação integral do ser humano, ou seja, estratégias que ampliem o repertório cognitivo, motor, emocional e sensível dos/as estudantes, com vistas à transformação da realidade. Com base em tal pressuposto, este artigo está circunscrito à experiência pedagógica de construção de uma cúpula geodésica, em processo desenvolvido na Educação Básica Técnica e Tecnológica, no Instituto Federal de Educação, Ciência e Tecnologia Sul-riograndense, Campus Pelotas - Visconde da Graça (IFSul/CaVG). Tal experiência configura-se como inovadora estratégia metodológica para o desenvolvimento da Educação Ambiental (EA) e da Educação Estético-Ambiental (EEA).

Inicialmente projetado e desenvolvido por três alunos do Curso Superior em Gestão Ambiental do IFSul/CaVG, o processo de construção da cúpula geodésica, logo após a finalização do recesso acadêmico do campus, contou com a participação e o apoio de professoras e de alunos/as dos Cursos Técnico Integrado e Subsequente em Meio Ambiente.

Concernente à EA desenvolvida no âmbito do ensino formal, Muñoz (1996) destaca que seu objetivo é proporcionar experiências de aprendizagem que propiciem a compreensão das relações dos seres humanos e não humanos. Para a autora, as práticas pedagógicas de EA, ao estimularem a participação ativa e solidária, promovem, por meio do exercício da cidadania, a busca por soluções para os problemas ora postos, configurando-se, dessa forma, como um movimento ético e estético de transformação.

Os princípios orientadores das práticas pedagógicas de EA no ensino formal engendram o caráter transformador e de desenvolvimento da autonomia da educação e incitam a articulação das diversas dimensões da EA, dentre elas a natural, a social, a política, a econômica e a cultural. Outros elementos, como a sensibilidade e a criatividade, não estão presentes de forma explícita nos documentos que legitimam o campo da EA (Estévez, 2011), porém, eles compõem o conjunto de elementos que integram a dimensão estética da EA.

A EEA, de acordo com Alvarez, Schmidt e Estévez (2017), emerge da educação em valores e busca, por meio de uma abordagem holística e de práticas de sensibilização, a reforma do pensamento e também da escola. Nesse sentido, estimula e promove mudanças de comportamento, contribuindo, assim, para o enfrentamento e a superação dos problemas socioambientais atuais. Segundo os autores,

[...]puede decirse que la Educación Estético-Ambiental constituye un imperativo de la educación en las condiciones de la crisis socio-ambiental contemporánea, pues propone la sensibilización estético-ambiental de la personalidad en función de una educación integral, que concibe al ser humano como una totalidad (poseedor de una conciencia unitaria donde se interrelacionan - se integran - la mente racional y la mente emocional: emociones, sentimientos, valores, ideales, convicciones, conceptos, etcétera) (Alvarez, Schmidt e Estévez, 2017, p. 195).

Com esse mesmo viés, Silveira, Freitas e Estévez (2020, p. 33) consideram que a EEA é "o conjunto de práticas, saberes, conhecimentos e metodologias de caráter pedagógico, destinadas a enriquecer o relacionamento emocional das pessoas com o nosso meio ambiente". Torna-se, pois, pertinente o estudo de estratégias pedagógicas inovadoras voltadas ao desenvolvimento integral do ser humano. Estratégias pedagógicas que favoreçam e estimulem a conexão da razão com a emoção, do intelecto com o sensível e que, em acordo com Estévez (2020), ampliem a fusão entre a estética e o ambiente, como ocorre na construção de uma cúpula geodésica. 
A cúpula geodésica é um tipo de construção que, utilizando os fundamentos da geodesia e conceitos da geometria, intenta causar o menor impacto ambiental, tendo como princípio a economia de recursos materiais. De acordo com Verschleisser (2008), as cúpulas geodésicas, ou domos geodésicos, ganharam destaque a partir do século XX, sendo um invento idealizado e patenteado por Richard Buckminster Fuller, arquiteto e inventor americano.

O domo geodésico é considerado por muitos o maior invento do século 20 em termos de estrutura. É um sistema sinérgico. Seu objetivo essencial é a eficiência. Nessa linha de raciocínio, o ideal de Fuller era alcançar "a maneira mais eficiente pela qual uma organização possa fazer o trabalho de $100 \%$ da humanidade no menor tempo possível, utilizando a cooperação espontânea e sem causar prejuízos a ninguém nem danos ecológicos". Nada mais atual: é o que hoje conhecemos por meio de expressões como "comprometimento compartilhado", "sustentabilidade", "responsabilidade sócio-ambiental" e afins (Mariotti, 2008, p. 2).

Diferente de projetos arquitetônicos convencionais, uma cúpula geodésica é construída desde o seu ponto mais alto, ou seja, do topo para a base. A partir desse ponto central, vão sendo acrescentadas as vigas, as quais vão permitindo que a estrutura se erga e crie forma. Neste sentido, a cúpula vai saindo do chão, vai subindo. Para essa construção progressiva, são fundamentais a participação, a colaboração e o trabalho coletivo, princípios orientadores das práticas pedagógicas em EA e EEA.

\section{Caminho Metodológico}

Esta investigação, de natureza qualitativa é caracterizada com um estudo de caso que, para Pereira et al. (2018, p. 65) "é uma descrição e análise, a mais detalhada possível, de algum caso que apresente alguma particularidade que o torna especial". Contou com a participação dos três alunos idealizadores do projeto de construção da cúpula geodésica e das cinco professoras que participaram da sua construção e instalação no IFSul/CaVG, no município de Pelotas, RS. Seus codinomes, escolhidos pelos/as próprios/as participantes da pesquisa, são: Pedro, Henrique, Roger, Ana, Maria, Simone, Rebeca e Joana. Todos/as assinaram o termo de consentimento livre e esclarecido e a autorização para uso de imagem. A autorização para uso de imagem foi assinada pelas demais pessoas que aparecem nas fotografias.

Para a produção das informações foi utilizado o diário de campo escrito à época da construção por uma das autoras deste artigo e a entrevista semiestruturada. Tal entrevista foi elaborada com perguntas distintas para alunos e professoras, recorrendo-se à fotografia como dispositivo de acionamento da memória. Os registros fotográficos feitos durante o processo de construção e instalação da cúpula geodésica do IFSul/CaVG, do acervo pessoal das autoras, foram dispostos sobre a mesa no momento das entrevistas, possibilitando o aflorar de lembranças do vivido e dos sentimentos pelos participantes da investigação.

As entrevistas tiveram como questões orientadoras aspectos relacionados à construção da cúpula geodésica, as quais serviram como bússola da conversa, para que não houvesse dispersão do foco da investigação. Assim, dois conjuntos de questionamentos foram organizados: um para os estudantes que elaboraram o projeto de construção e construíram a cúpula geodésica do IFSul/CaVG e outro para as professoras do IFSul/CaVG que estiveram envolvidas na referida construção.

As informações foram analisadas a partir da metodologia de Análise Textual Discursiva (ATD), proposta por Moraes e Galiazzi (2011), tendo como ferramenta, para uma melhor sistematização e organização das informações, o software NVivo Pró 12.

A ATD é uma metodologia de análise que transita entre a análise de conteúdo e a análise do discurso. Busca a compreensão e a reconstrução de um fenômeno ou discursos, tendo a escrita como o movimento de organizar e sistematizar o pensamento, bem como de construir o conhecimento, possibilitando a compreensão acerca do fenômeno investigado. Na ATD, 
o corpus de análise é fragmentado e codificado com letras e números em unidades de sentido e significado, as quais possibilitam o emergir de categorias iniciais, intermediárias e finais, sucessivamente.

\section{Resultados e Discussão}

Foi na magia do trabalho coletivo, alegre e divertido de construção da cúpula geodésica do IFSul/CaVG, como numa brincadeira de roda e com a força do trabalho, empenho e dedicação, que professoras e alunos/as, aprenderam na e pela partilha. Motivaram-se coletiva e mutuamente diante dos desafios que se apresentaram durante a brincadeira e acenderam ou fizeram renascer a chama da esperança por uma educação que possibilite a nossa transformação e também do nosso entorno.

Para Freire (1996), a alegria e a esperança são sentimentos necessários ao fazer educativo, pois propiciam a instauração de um ambiente de aula favorável ao ensino e à aprendizagem. Dito de outro modo, ambos sentimentos contribuem para fazer do espaço pedagógico um lugar de partilha e de crescimento pessoal e coletivo. Para o autor,

[h]á uma relação entre a alegria necessária à atividade educativa e a esperança. A esperança de que o professor e alunos juntos podemos aprender, ensinar, inquietar-nos, produzir e juntos igualmente resistir aos obstáculos a nossa alegria. [...] A esperança é um condimento indispensável à experiência histórica (Freire, 1996, p. 72).

Esses dois sentimentos, alegria e esperança, estiveram presentes durante todo o processo de construção da cúpula geodésica do IFSul/CaVG e nas atividades pedagógicas que lá foram desenvolvidas. Na Figura 1, a fotografia mostra a felicidade expressa no sorriso dos/as alunos/as no momento em que, juntos/as, trabalhavam de maneira colaborativa e protagonista na construção da cúpula geodésica, com o desejo e a esperança da concretização de um objetivo comum.

Figura 1 - Alunos/as na construção da cúpula geodésica.

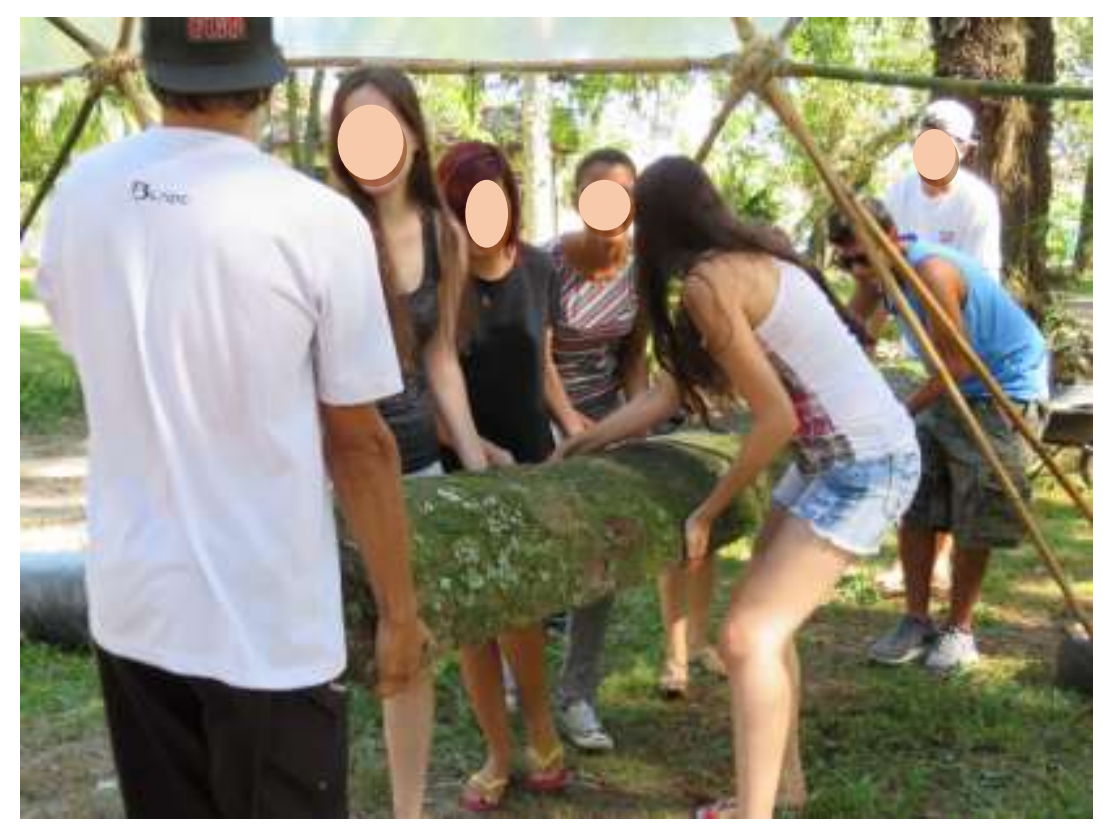

Fonte: Acervo pessoal da pesquisadora (2016).

Essa fotografia foi uma das escolhidas pelo aluno Pedro e pela professora Rebeca, quando, no início das entrevistas realizadas, os registros fotográficos de todo o processo foram dispostos sobre a mesa como dispositivos para acessar a memória. A fotografia expressa o esperançar proposto por Freire. Esperançar no sentido de acreditar e de fazer, de pôr a mão 
na massa, de enfrentar os desafios para realizar os sonhos. Pedro, com os olhos brilhando de emoção e orgulho, justificou sua escolha pela fotografia dizendo que

[...] foi o início de todas as atividades. É muito gratificante também ver a aceitação e animação da galera em participar de tudo que rolava por lá. Nos mostrou que tinha mais gente com coração verde e que pensava e olhava para o mesmo lado (PED006).

O apoio e o empenho dos/as demais alunos/as, bem como sua participação efetiva nas atividades realizadas na cúpula geodésica, fez com que Pedro percebesse que não estava sozinho na busca por alternativas para a superação dos problemas socioambientais vigentes. O processo de construção da cúpula geodésica mostrou, como disse Pedro, "que tinha mais gente com o coração verde e que pensava e olhava para o mesmo lado". Ter o coração verde e pensar e olhar para o mesmo lado foi uma forma metafórica manifestada por Pedro para identificar pessoas compromissadas com as causas ambientais, ou seja, para identificar potenciais educadores ambientais. Ainda, como expresso por Pedro, saber que outras pessoas são e estão engajadas em questões ambientais é um fator de motivação e estímulo para fortalecer o empenho no enfrentamento dos problemas socioambientais.

Já a professora Rebeca justificou a escolha da fotografia acima (Figura 1) por ser o registro do entusiasmo, da determinação, do protagonismo e da autonomia dos/as alunos/as durante a construção da cúpula geodésica. Para ela, a alegria, a vontade e o empenho dos/as alunos/as, durante todo o processo de construção, foi fundamental para contagiar professores/as e comunidade em geral. Ao observar a fotografia, a professora, sorrindo, comentou que "os olhos deles brilhavam tanto, era tão cativante, eles passavam aquela coisa boa do 'vamos fazer, vamos tocar para frente, vamos executar"” (REB101).

A valorização e o reconhecimento da autonomia e do protagonismo dos/as alunos/as durante a construção da cúpula geodésica, como disse Rebeca, coaduna-se com a educação transformadora proposta por Freire (1996). Para o autor, o incentivo à autonomia dos/as alunos/as é imprescindível à educação transformadora pois, "[o] respeito à autonomia e à dignidade de cada um é um imperativo ético e não um favor que podemos ou não conceder uns aos outros” (Freire, 1996, p. 59).

Além disso, a mobilização e a determinação dos/as alunos/as, como apontado pela professora Rebeca ao dizer que "os olhos deles brilhavam tanto [e que o movimento] era tão cativante", estimulou outras professoras a se envolverem na construção e, por consequência, a engendrarem um movimento de transformação e renovação, tanto do cenário educativo do campus como das práticas pedagógicas desenvolvidas nos cursos da área ambiental do IFSul/CaVG.

Dessa forma, o envolvimento e a participação de professoras e alunos/as na construção e implantação da cúpula geodésica no IFSul/CaVG podem ser entendidos como uma significativa estratégia para o desenvolvimento da EEA no ensino formal e para a formação de educadores ambientais. Para Loureiro (2006), o desenvolvimento da EA, numa perspectiva histórica e crítica, demanda reflexão acerca da realidade e de ações conscientes com vistas à transformação social, tal como ocorreu durante o movimento de construção da cúpula geodésica e nas atividades pedagógicas nela desenvolvidas.

De acordo com Loureiro (2006), a EA é essencial a todo processo pedagógico que tenha como objetivo o desenvolvimento do ser humano. O ser humano é compreendido pelo autor como ser da natureza. Nessa linha de pensamento, a EA enquanto dimensão do ensino, necessita ser desenvolvida considerando as relações sujeito-meio na complexidade da realidade.

Além de possibilitar a ampliação da discussão e a problematização de questões socioambientais, o movimento de construção da cúpula geodésica, ao configurar-se como ação coletiva e consciente, foi eficaz para a transformação do ambiente escolar e para o desencadeamento de novas práticas educativas em EA. Reigota (2011) sublinha que o papel da escola deva ser o de tornar-se um centro de questionamentos e de produção de alternativas para as demandas da atualidade. Para o autor, 
[a] tendência da educação ambiental escolar é tornar-se não só uma prática educativa, ou uma disciplina a mais no currículo, mas sim consolidar-se como uma filosofia de educação, presente em todas as disciplinas existentes e possibilitar uma concepção mais ampla do papel da escola no contexto ecológico local e planetário contemporâneo (Reigota, 2011, p. 82)

Ao comentar sobre o envolvimento e a participação das professoras no processo de construção da cúpula geodésica e na elaboração e execução de atividades pedagógicas para o desenvolvimento da EA, a professora Ana destacou a relevância do trabalho coletivo e integrador ao dizer o seguinte:

Aí nós conseguimos unir ali uma equipe boa para trabalhar. Todo mundo pegou junto (ANA063).

As professoras que utilizaram o espaço também, com um ambiente, um local de ensino, que tinham um mesmo objetivo, trabalharam juntas (ANA058).

[...] nós trabalhamos juntos, cada um com as suas ideias, dentro da sua disciplina, mas usando o espaço para o mesmo objetivo: a educação ambiental, o ensino e a educação (ANA080).

Para a professora, a participação na construção da cúpula geodésica e nas atividades lá realizadas possibilitou a integração e interação de diferentes campos do conhecimento e do desenvolvimento da EA, de forma interdisciplinar e transdisciplinar. A fala de Ana, "nós trabalhamos juntos, cada um com as suas ideias, dentro da sua disciplina, mas usando o espaço para o mesmo objetivo, a educação ambiental, o ensino e a educação", demonstra quão potente é a utilização de uma cúpula geodésica para o trabalho interdisciplinar em EA, tal como é estipulado nos documentos que regulamentam a EA, como a PNEA (Brasil, 1999) e as DCNEA (Brasil, 2012) e em consonância com o entendimento do que seja a interdisciplinaridade, conforme Rios (2010). A autora destaca que a interdisciplinaridade é mais do que a simples junção de disciplinas, pois

[...] existe interdisciplinaridade quando se trata verdadeiramente de um diálogo, ou de uma parceria, que se constitui exatamente na diferença, na especificidade da ação de grupos ou indivíduos que querem alcançar objetivos comuns, que "jogam" em posições diferentes num mesmo "time” (Rios, 2010, p. 58).

O pensamento de Reigota (2011) e o de Munõz (1996) fortalecem essa afirmativa, no sentido de que o processo de construção e de utilização da cúpula geodésica possibilitou que a EEA se fizesse presente em várias disciplinas dos cursos da área ambiental do IFSul/CaVG. A integração da comunidade acadêmica, em atividades de extensão, extrapolou os limites geográficos do campus, promovendo, como indicado pelos autores, uma ampliação do papel da escola.

A existência da disciplina Fundamentos da Educação Ambiental Formal e Não Formal na matriz do Curso Superior em Gestão Ambiental do IFSul/CaVG, em acordo com o Artigo 8, parágrafo único, das DCNEA (Brasil, 2012), é um importante espaço para a discussão e problematização de questões ambientais. Não obstante, ter a disciplina na matriz curricular não é garantia do fomento à discussão, reflexão crítica e proposição de ações ambientais, como sinalizou a professora Rebeca ao comentar sobre a disciplina que ministrava.

Educação formal, para mim era mais simples, né? Discutir com os alunos, contar para eles o que era a educação ambiental formal e como que ela era vista, e mostrar a legislação onde ela era citada (REB 030).

Agora, a educação ambiental não formal era um pouco mais difícil (REB 031).

Então, o que eu pensei? Eu vou fazer com que eles vivenciem a não formal dentro do formal (REB 032). 
Porque se eu não instigasse isso neles, ia acabar que ia ser só mais uma disciplina, que as criaturas iam ficar ali, escutando o professor falar, um certo debate minimamente profundo. Aliás, minimamente profundo não, aqueles debates bem rasos (REB 033).

O comentário da professora coaduna-se com as polêmicas discussões de educadores ambientais sobre a temática, nas últimas décadas, quando problematizam sobre o fato de que não basta ter uma disciplina específica para que a EA seja desenvolvida de forma crítica e reflexiva no ensino formal. Como o sistema de ensino brasileiro tem caráter disciplinar, a inclusão de uma disciplina específica de EA no currículo poderia configurar-se como um espaço privilegiado para a discussão sobre as questões socioambientais. Porém, como salientou Rebeca, ter a disciplina não é garantia do desenvolvimento de uma EA crítica e transformadora, tampouco da EEA. É necessário disposição e motivação do/da professor/a para que a EA não seja mais uma disciplina no currículo, como expressou a professora ao refletir sobre a sua prática pedagógica em EA. Quando Rebeca diz: "se eu não instigasse isso neles, ia acabar que ia ser só mais uma disciplina, que as criaturas iam ficar ali, escutando o professor falar, um certo debate minimamente profundo", ela indica que o desenvolvimento de uma EA crítica e reflexiva é dependente da motivação pessoal do/a professor/a e dos/as alunos/as e não deriva necessariamente da mera existência da disciplina. É fundamental que se avance em direção à transversalidade, tal como indicado nos documentos que regulamentam a EA e traçam diretrizes para sua integração no currículo.

O desenvolvimento da EA de forma transversal, inter e transdisciplinar, pôde ser experimentado durante o processo de construção da cúpula geodésica do IFSul/CaVG, como disse Pedro, ao comentar sobre a motivação para a construção da cúpula geodésica e a sua potência para o ensino interdisciplinar e transdisciplinar.

A ideia era de fazer algo diferente, de fazer algo que ninguém nunca fez na escola. De transformar uma maneira de ensino, de transformar uma simples disciplina numa coisa que foi além, numa interação entre todo mundo, numa maneira de abordar o curso, de abordar a disciplina de educação ambiental, abordar tudo (PED037).

Porém, o movimento da construção não começou de forma integrada e articulada. A integração se deu durante o processo de construção e foi crescendo com o tempo e com a experiência vivida. Foi a partir da experiência, conforme Larrosa (2015), com e na construção, que professoras e alunos/as se sentiram tocados/as e mobilizados/as para dar seguimento a uma ideia, originariamente proposta por três alunos e que teve como estopim, para a sua concretização, uma resposta dada em forma de pergunta: "Por que não?" (REB 130).

Essa foi a resposta da professora Rebeca aos alunos quando questionada sobre a possibilidade de execução do projeto de construção da cúpula geodésica apresentado na sua disciplina. Para a professora, que havia proposto como atividade avaliativa o desenvolvimento de um projeto de ação ambiental junto às comunidades dos/as alunos/as ou no próprio campus, com o objetivo de identificar possíveis transformações nesses contextos, sua resposta, entendida como um sim, impulsionou o início da construção da cúpula geodésica do IFSul/CaVG.

Ao comentar sobre o começo da construção, a professora Rebeca, orgulhosa de seus alunos, disse: "eu não sabia nem o que era direito a geodésica" (REB, 135) e completou dizendo, "se aquele grupo de alunos estava me fazendo uma proposta dessas, é porque algum fundamento tinha" (REB,136).

A fala de Rebeca reforça a importância da escuta e da atenção - pressupostos da educação transformadora - em atividades pedagógicas. Ao possibilitar que os alunos expressassem a vontade de executar o seu projeto de construção, a professora soube escutar, propiciar voz e vez aos alunos e aprender com eles.

Para Freire (1996), saber escutar é uma exigência ao/à professor/a transformador/a, já que a escuta atenta é parte do diálogo com o outro, do falar com e não para o outro. "[...] é escutando que aprendemos a falar com eles. Somente quem escuta paciente e criticamente o outro, fala com ele, mesmo que, em certas condições, precise falar a ele" (Freire, 1996, p.113, 
grifos do autor). E foi no transcorrer do diálogo e do aprendizado mútuo que professoras e alunos/as vivenciaram a experiência de construção da cúpula geodésica no IFSul/CaVG. Dúvidas e insegurança fizeram parte do processo de construção, não obstante foram superadas coletivamente, como relatou Joana:

Mas de onde tiraram isso? Como se faz? Como que é? Como assim, vão construir com bambu? Como assim? Vai cair? Não vai cair? Sabe, aquela função toda. E aí tu vês que dá certo o negócio. Pô, mas que bacana! E começa a te envolver cada vez mais. (JOA052)

O envolvimento das professoras foi engendrado paulatinamente, causando estranhamento, em certos momentos, e noutros, vontade de estar junto, de querer fazer. Freire (1996) entende que o risco e a aceitação do novo fazem parte dos processos de ensinar e que, mesmo causando desconforto, não podem ser limitadores das práticas educativas. Segundo o autor, como seres inconclusos e inacabados, devemos estar sempre abertos ao novo e ao desconhecido.

A professora Maria relatou que, a princípio, também sentiu insegurança no que concerne à efetivação da construção da cúpula geodésica e que não valorizou sobremaneira a proposta dos alunos, por entender que o período de férias acadêmicas comprometeria o andamento da construção, haja vista que professore/as e alunos/as não costumam frequentar a Instituição nesse período. Ao comentar sobre o início da construção da cúpula geodésica no IFSul/CaVG, a professora Maria disse que: "no início também eu nem dei a devida importância, até mesmo porque foi em época de férias ali" (MAR021).

Os três alunos proponentes não mediram esforços para pôr em prática o projeto apresentado à professara Rebeca e, aproveitando a calmaria reinante no campus, decorrente do período de férias letivas, prepararam uma bela surpresa de volta às aulas. No início do ano letivo, a cúpula geodésica, em fase de finalização, estava visível, impactante e convidativa à comunidade do IFSul/CaVG, como mostra a Figura 2. A maioria dos/as professores/as e alunos/as foram surpreendidos/as com o que visualizaram no dia do retorno às atividades acadêmicas.

Figura 2 - Cúpula Geodésica na volta às aulas.

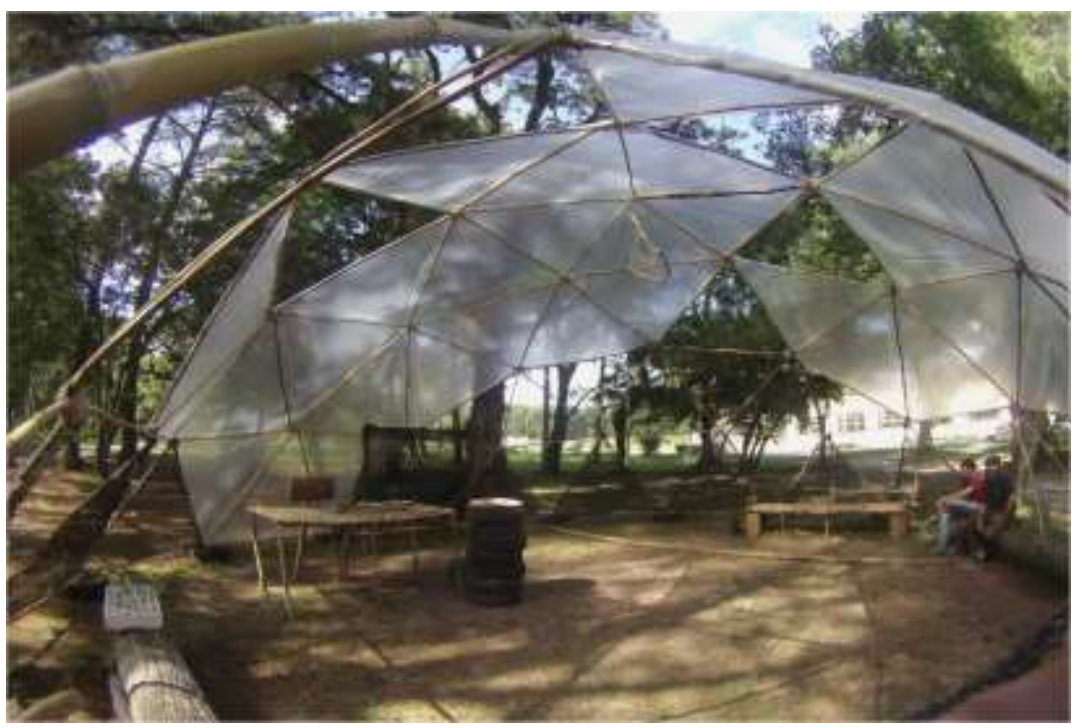

Fonte: Arquivo pessoal de Inti Schlee (2016).

Henrique, Pedro e Roger queriam deixar as suas marcas na Instituição, ser reconhecidos e valorizados, além de possibilitar aos demais, um lugar acolhedor e sustentável. As falas dos alunos Henrique e Roger mostram o quanto os alunos gostariam de ser reconhecidos e valorizados pelo trabalho desenvolvido e esperavam fazer novas amizades. 
A gente queria aprender, porque a gente queria fazer uma coisa maior, mais interessante. Foi o que agregou muito na gente, foi isso (HEN003).

A gente quer construir isso, a gente não queria saber de mais nada. (...) a gente queria era criar mais amigos, se destacar para fazer mais coisas (HEN004).

A gente queria fazer algo grande, que pelo menos, de alguma forma, marcasse a nossa passada aqui (ROG047).

E amizades surgiram, então me senti muito mais aluno, e aí eu podia fazer tudo que eu queria, sabe? Muitas ideias que a gente acabou fazendo foi assim, por se sentir aluno e por sentir que a gente faz parte disso aqui, dessa instituição (...). Bem aluno, na verdade. (HEN071)

Deixar marcas e fazer amigos/as, como destacaram Henrique e Roger, foram desejos que mobilizaram os alunos para a realização da construção da cúpula geodésica. As palavras de Roger, "a gente queria fazer algo grande, que pelo menos, de alguma forma, marcasse a nossa passada aqui", assim como as de Henrique, "me senti muito mais aluno", expressam a importância do vínculo com o lugar para o sentimento de pertencimento a ele, como sinalizaram Oliveira (2014) e Brandão (2005). Para Oliveira (2014), é a partir do vínculo com o lugar e do sentimento de pertencimento a ele que o ser humano se reconhece e fortalece como parte integrante do contexto em que está inserido. Já para Brandão (2005, p. 57), o sentimento de pertença a um contexto envolve "[a] capacidade de sentir-se parte de um mundo e de envolver-se em grupos, em equipes, em associações, cujo sentido está em alguma forma de presença e de participação".

No mesmo sentido, e buscando romper com o individualismo que Baumann (2005) afirma ser uma das destacadas marcas da modernidade líquida vigente nos tempos atuais, querer "se destacar para fazer mais coisas", como falou Henrique, reforça a importância do sentimento de pertencimento para a superação da crise socioambiental instaurada, tal como destacou Grün (2008). Além disso, ao expressar que gostaria de "criar mais amigos", Henrique apontou para a importância do estreitamento dos vínculos afetivos no cotidiano escolar.

Dessa mesma linha de pensamento, Rios (2010), ao estudar as demandas à filosofia e à didática na contemporaneidade destaca que um dos desafios à educação, em tempos onde a razão instrumental e o irracionalismo estão fortemente presentes, é estimular a afetividade no ambiente escolar. Para a autora, "é preciso encontrar o equilíbrio, fazendo a recuperação do significado da razão articulada ao sentimento e, no que diz respeito ao ensino, a reapropriação do afeto no espaço pedagógico" (Rios, 2010, p. 43).

A afetividade mostrou-se uma constante nas falas dos/as entrevistados/as quando comentavam sobre a construção da cúpula geodésica do IFSul/CaVG, como bem observou Rebeca ao dizer que o movimento de construção da cúpula geodésica "mexeu com tanta gente, cativou tanta gente, motivou tanta gente, convidou, pela simples existência. A geodésica convidou tanta gente a se aproximar" (REB033).

Mexer, cativar e motivar, ou seja, sensibilizar e aproximar pessoas para o trabalho coletivo, como destacou Rebeca, mostrou-se como estímulo à participação e envolvimento da comunidade do IFSul/CaVG e, também, como potência para o estreitamento da relação eu-vida, conforme Brandão (2005). Para o autor, essa relação se dá quando o ser humano se sente conectado com o todo. "Toda emoção e todo pensamento significativo surgem e ganham sentido em contextos que vão do interior (eu comigo) ao interativo (eu com um outro) e ao recíproco, o coletivo, o solidário, o social (nós entre os outros)" (Brandão, 2007, p. 145).

No início da entrevista, enquanto observava as fotografias expostas sobre a mesa, a professora Ana, relembrando a experiência vivida, refletindo sobre o trabalho desenvolvido e sobre as amizades feitas à época, destacou que a construção da cúpula geodésica permitiu o engajamento de professoras e alunos/as, que juntos/as empenharam-se para fazer da cúpula geodésica um lugar de ensino e de aprendizagem, de ação e de reflexão, de partilha, de afeto e de sonhos. Para ela, "foi um 
período muito legal em termos de convivência. Em termos de nós conseguirmos desenvolver o trabalho, a parceria toda que nós tivemos ali, para conseguir fazer esse projeto" (ANA001).

A fala da professora Ana sintoniza com a do aluno Pedro com relação à partilha e à integração de saberes. Para ele, o processo de construção da cúpula geodésica possibilitou "uma troca de conhecimento, uma troca de ideia em tudo, envolvendo música, envolvendo arte, envolvendo educação, educação ambiental sustentabilidade, de tudo" (PED045).

A professora Joana também salientou o quanto o movimento de construção da cúpula geodésica do IFSul/CaVG contribuiu para a aproximação da comunidade acadêmica como um todo e, em especial, para a aproximação de alunos/as e do corpo docente da instituição. Ela manifestou sua percepção da seguinte forma:

Tudo bem, é importante ter ali o grupo envolvido no processo, mas mais importante que isso é o aparecimento de alunos também na construção. Porque teve outras turmas de alunos que participaram da construção. Então para mim isso é bastante importante (JOA065).

Eu acho que foi importante para a nossa aproximação, aproximação de professores de nível técnico e superior. Acho que foi superimportante (JOA102).

Para a professora, o envolvimento na construção da cúpula geodésica contribuiu para diminuir o distanciamento entre os/as professores/as, levando-os/as a dialogar e partilhar conhecimentos e experiências. Considerou que "foi importante para a nossa aproximação, aproximação de professores de nível técnico e superior”, promovendo, dessa forma, o estreitamento dos vínculos entre os/as professores/as dos cursos da área ambiental da instituição. Segundo palavras da professora, o mesmo ocorreu com os/as alunos/as, favorecendo a integração de estudantes de diferentes níveis de ensino.

Ao serem estimulados/as à participação na construção da cúpula geodésica e nas atividades pedagógicas planejadas para nela serem desenvolvidas, os/as alunos/as, de imediato, aceitaram o convite, conforme disse Simone.

Eu coloquei para os alunos em sala de aula. Perguntei se eles tinham interesse. Expliquei o que era o projeto e todos eles, unanimemente, quiseram participar. E aí nós começamos a organizar, até num plano de ensino, para poder colocar as idas, a participação na geodésica (SIM002).

Contar com a participação dos/as alunos/as, como falou a professora Simone, estimulou a formalização institucional das atividades realizadas na cúpula geodésica, via elaboração de um "plano de ensino, para poder colocar as idas, a participação na geodésica". O registro formal de atividades em EA sob a forma de projetos é, segundo Munõz (1996), uma das vias para a reflexão acerca de questões socioambientais no ensino formal. Para a autora,

[a]l carácter integrador de la E.A. conviene muy bien el trabajo sobre proyectos globalizados, que permiten a las distintas materias transitar por determinados problemas sin necesidad de recargar sus contenidos, sino de tratarlos de otro modo, de aplicar conocimientos y destrezas y de dirigirlos a la solución de problemas y a la acción (Muñoz, 1996, p.30).

Assim, tanto o projeto inicial de construção da cúpula geodésica como os projetos engendrados a partir dele mostraram-se potentes estratégias para o desenvolvimento da EEA na Educação Básica e, como numa brincadeira de roda, desencadearam a união, o diálogo, o trabalho coletivo, a participação, o engajamento, a afetividade e a sensibilidade.

\section{Considerações Finais}

O processo de construção de uma cúpula geodésica constitui-se em atividade pedagógica que atende aos princípios freirianos e contempla os pressupostos e objetivos da EA e da EEA, já que ambos comungam da necessidade do 
desenvolvimento da criticidade, da autonomia, da tomada de decisão e do compromisso ético com a transformação social, bem como estimulam a integração dos diversos saberes a partir de práticas pedagógicas dialógicas e reflexivas.

A proposta de construção de uma cúpula geodésica, tal como mostraram os resultados dessa investigação, é uma estratégia pedagógica que possibilita o desenvolvimento de conteúdos de variados campos do conhecimento tornando-se, dessa forma, uma via potente para o trabalho interdisciplinar e transdisciplinar. A circularidade de uma cúpula geodésica suscita e potencializa a formação, a renovação e a transformação. Além disso, por ser uma atividade que não se realiza de forma individualizada, demanda diálogo, participação, cooperação e engajamento, contemplando, dessa forma, os princípios orientadores das práticas pedagógicas em EA.

Enquanto via para o desenvolvimento da EA, a construção de uma cúpula geodésica, ao fomentar o diálogo, incita a discussão e a problematização das relações ser humano-mundo, bem como estimula, por meio de um trabalho participativo e colaborativo, a incorporação de posturas ecológicas condizentes com uma sociedade justa, igualitária e sustentável, como sugerem Loureiro (2006) e Muñoz (1996).

Além de atender aos objetivos da EA, a construção de uma cúpula geodésica, ao possibilitar o contato com o belo e com o ambiente natural, amplia as possibilidades do desenvolvimento da sensibilidade, da criatividade humana e da percepção estética, efetivando-se como via potente para o desenvolvimento da EEA (Estévez, 2012; 2020). Tal construção também promove o desenvolvimento da corporeidade, ao colocar os corpos em movimento e em contato com o outro, humano e não humano. A dinâmica da construção de uma cúpula geodésica desperta e aguça os sentidos humanos, contribuindo para a promoção da educação dos sentidos (Duarte Jr, 2004).

A construção de uma cúpula geodésica, ao ser utilizada como atividade curricular no ensino formal, é um recurso metodológico que contribui para aproximar as pessoas, fortalecer o sentido de coletividade e aumentar o sentimento de pertencimento à comunidade escolar, fatores basilares de uma educação transformadora compromicssada com a formação humana e a transformação social.

Os resultados da pesquisa evidenciaram que a construção de uma cúpula geodésica, ao demandar a constante açãoreflexão-ação, coaduna-se com o sentido de práxis, conforme Freire (1996, 2011), favorecendo a ampliação dos horizontes discente e docente. No mesmo viés, ao ser permeada pela afetividade, rigorosidade metódica e curiosidade, a construção de uma cúpula geodésica suscita o "amor armado" (Freire, 1997) e incita a realização de novos fazeres pedagógicos.

O trabalho de construção da cúpula geodésica, de forma colaborativa e participativa, onde todos os/as envolvidos/as aprendem e fazem juntos/as, discutem e refletem em grupo vem ao encontro do que afirma Freire (1996) ao se referir à importância do/da professor/a sentir-se sujeito em constante processo de formação, que ao ensinar aprende, se faz e se refaz e de considerar os/as alunos/as também como sujeitos desse processo e não como objetos. A construção de uma cúpula geodésica reafirma o pensamento freiriano de que ensinar não é apenas transmitir conhecimentos, mas aprender junto, compartilhar saberes e experiências. Nesse processo, nessas trocas, ambos, professores/as e alunos/as, aprendem e se transformam.

Por fim, sinalizamos para a necessidade de novas investigações a respeito da instalação de cúpulas geodésicas no interior das escolas brasileiras, já que as mesmas, como mostraram os resultados dessa investigação, renovam e reconfiguram o ambiente educativo, bem como suscitam novas práticas educativas, ampliando possibilidades de uma formação humanizada, sensível, crítica e participativa a fim da transformação da realidade.

\section{Referências}

Alvarez, L. E.;Schmidt, E. B. \& Estévez, P. R. (2017). La educación estético-ambiental como un imperativo de la educación en las condiciones de la crisis socio-ambiental contemporánea. REMEA - Revista Eletrônica do Mestrado em Educação Ambiental, 1(34), 186-200. https://periodicos.furg.br/remea/article/view/6627/4459 
Research, Society and Development, v. 10, n. 2, e44010212811, 2021

(CC BY 4.0) | ISSN 2525-3409 | DOI: http://dx.doi.org/10.33448/rsd-v10i2.12811

Bauman, Z. (2005). Identidade: entrevista a Benedetto Vecchi. Jorge Zahar.

Brandão, C. R. (2005). As flores de abril: movimentos sociais e educação ambiental. Autores Associados.

Brandão, C. R. (2007). O vôo da arara azul. Escritos sobre a vida, a cultura e a educação ambiental. Armazém do Ipê.

Brasil. Lei $n^{\circ}$ 9.795, de 27 de abril de 1999. Dispõe sobre a educação Ambiental, institui a Política Nacional de Educação Ambiental - PNEA e dá outras providências. http://www.planalto.gov.br/ccivil_03/leis/19795.htm.

Brasil. Resolução n. 2, de 15 de junho de 2012. Dispõe sobre as diretrizes curriculares nacionais para a Educação Ambiental. http://portal.mec.gov.br/dmdocuments/rcp002_12.pdf.

Duarte Jr, J. F. (2004). O sentido dos sentidos. A educação (do) sensível. (3a ed.). Criar Edições.

Estévez, P. R. (2011). Educar para el bien y la beleza. Editora da FURG.

Estévez, P. R. (2012) La educación estética: conceptos e contextos. Editorial Capiro.

Estévez, P. R. (2015). Enseñar a sentir. Editorial Pueblo y Educación.

Freire, P. (1996). Pedagogia da autonomia. Paz e Terra.

Freire, P. (1997). Professora sim, tia não: cartas a quem ousa ensinar. Olho d'água. https://nepegeo.paginas.ufsc.br/files/2018/11/Paulo-Freire-Professorasim-tia-n\%C3\%A3o-Cartas-a-quem-ousa-ensinar.pdf.

Freire, P. (2011) Pedagogia do oprimido. (50a ed.). Paz e Terra.

Grün, M. (2018). A importância dos lugares na Educação Ambiental. REMEA - Revista eletrônica do mestrado em Educação Ambiental. (especial), 1-11. https://periodicos.furg.br/remea/article/view/3384/2030.

Larrosa, J. (2015). Tremores: escritos sobre experiência. Autêntica Editora.

Loureiro, C. F. B. (2006). Trajetória e fundamentos da Educação Ambiental. (2a ed.). Cortez.

Mariotti, H. (2008). Sinergia, criatividade e complexidade. http://pavoniking.hospedagemdesites.ws/imagens/trabalhosfoto/442008_sinergia.pdf.

Moraes, R. \& Galiazzi, M. do C. (2011) Análise Textual Discursiva. (2a ed.) Unijuí.

Muñoz, C. G. (1996). Principales tendencias y modelos de la EA en el sistema escolar. Revista Iberoamericana de Educación, (11). $13-74,1996$.

Oliveira, L. de. (2014) O sentido de lugar. In: Marandola JR., E; Holzer W. \& Oliveira, L. de (Org). Qual o espaço do lugar? Perspectiva.

Pereira, A. S., Shitsuka, D. M., Parreira, F. J., \& Shitsuka, R. (2018). Metodologia da pesquisa científica UFSM. https://repositorio.ufsm.br/bitstream/handle/1/15824/Lic_Computacao_Metodologia-Pesquisa-Cientifica.pdf?sequence=1.

Reigota, M. A floresta e a escola: por uma educação ambiental pós-moderna. (4a ed.). Cortez.

Rios, T. A. Compreender e ensinar: por uma docência da melhor qualidade. (8a ed.). Cortez.

Silveira, W. T.; Freitas, D. P. S. de \& Estévez, P. R. (2020). O que é a Educação Estético-Ambiental? In: Freitas, D. P. S. de; Brizolla, F.; Mello, E. M. B.; Oliveira \& N. R. M. de (Org). Experiências didático-pedagógicas com educação estético-ambiental na formação acadêmico-profissional. Diálogo Freiriano. http://e-books.contato.site/ambiental.

Verschleisser, R. (2008). Aplicação de Estruturas de Bambu no Design de objetos: como construir objetos leves, resistentes, ecológicos e de baixo custo. [Tese de Doutorado, Pontifícia Universidade Católica do Rio de Janeiro]. https://www.maxwell.vrac.pucrio.br/Busca_etds.php?strSecao=resultado\&nrSeq=12258@1. 